\title{
The Role of Morphological Awareness in Reading Comprehension in Chinese EFL Adult Learners
}

\author{
Yaxi Cheng ${ }^{1, *}$
}

\author{
${ }^{1}$ School of Arts and Social Sciences, University of Sydney, Sydney, New South Wales 2006, Australia \\ *yche7553@uni.sydney.edu.au
}

\begin{abstract}
Phonological awareness seems to be paid more attention to in the past few years. Morphological awareness also has a unique impact after controlling for phonological awareness in Chinese and English acquisition, especially for Chinese EFL adult learners. Morphological awareness has its unique position in the cultivation of English reading ability, and it is also the key and foundation of Chinese reading development. Morphological awareness may be more suitable for Chinese EFL adult learners because it is similar to the learning method of their mother tongue. This review discusses the relationship between morphological awareness and reading comprehension in native speakers and then argues the relationship between morphological awareness and English reading comprehension of Chinese EFL adult learners. It also focuses on how to more effectively train morphological awareness to improve reading comprehension in the following parts. Indeed, the impact of morphological awareness on reading development includes direct and indirect influences. Due to the understanding of the relationship between morphological awareness and Chinese EFL adult learners' reading comprehension plays an important role in Chinese EFL adult learners' reading comprehension, so effectively intervening in morphological awareness to improve reading ability is also very significant. The existing reading theories are mainly concerned with reading models and reading development, but the research on morphological awareness is limited. For example, few theoretical studies on morphological awareness have paid attention to Chinese EFL adult learners. The systematic investigations about Chinese learners morphological awareness training are also lack and most of the studies use cross-sectional research. That makes the research unable to discover and understand the development of morphological awareness and the dynamic changes between morphological awareness and reading comprehension.
\end{abstract}

Keywords: morphological awareness, reading comprehension, English language learners.

\section{INTRODUCTION}

Morphological awareness is the conscious awareness of the morpheme structure of words and their ability to manipulate the structure [1]. English morphemes are the smallest meaningful part of language and words. Complex words emerge from combining morphemes in different ways [2]. Therefore, morphological awareness also has an important position in English learning. Learners can acquire the language by means of derived words, affixes, and so on. In addition, reading, vocabulary acquisition, spelling ability, and morphological awareness are likely to be related to individual reading development. Obviously, reading and vocabulary development are closely related, affecting morphological awareness [3]. In the study of McBride et al., they found a strong correlation between morphological awareness and vocabulary, indicating that vocabulary ability may promote morphological skills, and morpheme knowledge may help expand vocabulary knowledge [4]. Morphological awareness determines the recognition of words to a certain extent [4]. The faster individual recognizes a word, the smoother they can read. Meanwhile, studies have shown that the importance of morphological awareness to reading may also relate to the child's level of development [5]. The more complex language they learn, the more important morphological awareness to reading. Morphological awareness uniquely predicts more reading comprehension and spelling ability than phonological awareness [6].

Compared with English acquisition, Chinese has unique morphological characteristics because each morpheme in Chinese usually represents a syllable [4]. 
Moreover, there are about 7,000 characters in Chinese representing the morphemes used in daily life [7], and only about 1,300 different spoken morphemes [8], so there are a lot of homophones homonyms and homographs in Chinese, which makes morphological consciousness really essential in using and reading Chinese. Most Chinese characters consist of two parts, one part is the form part, and the other part is the meaning part. Studies have shown that children in the third and fifth grades are more sensitive to the meaning of semantic radicals [7]. This sensitivity is actually a vital aspect of the use of this morpheme awareness. Therefore, morphological awareness plays a significant role in the reading, spelling, and recognition of Chinese beginners.

Morphological awareness has its unique position in English acquisition, while morphological awareness is also critical and fundamental for Chinese learning. Thus, it may be easier for adult EFL learners to adopt a morphological awareness approach to learn English, according to the importance of morphological awareness in their mother tongue. Meanwhile, educators understand the impact of morphological awareness on Chinese EFL adult learners' English learning to design better educational instructions to improve language learning effectiveness in the future.

Reading comprehension refers to the textual mental image construction generated by the interaction between the text content and the reader's cognitive process through the interaction of vocabulary knowledge, reasoning ability, word reading, working memory, background knowledge, and so on [9]. Song explained that certain reading strategies improve reading comprehension, and foreign language reading should include clear strategy training [10]. Indeed, reading can be divided into extensive reading and intensive reading. Extensive reading can be summarized as skimming and scanning, which helps expand learners' reading skills and gain independence through reading. In addition, students can improve their language skills, learn cultural knowledge, and enhance their confidence and motivation to continue learning through extensive reading [11]. Comparatively, intensive reading refers to learners find meaning and familiarizes themselves with learning strategies by reading, which focus on reading carefully. Through intensive reading, students can obtain basic exercises to implement these strategies based on a series of materials [11]. The exercises can be text-related or not. Therefore, intensive reading is often regarded as one of the effective ways to improve reading comprehension $[12,13]$.

Furthermore, there are three modes in EFL learning, including the bottom-up model, the top-down model, and the interactive model [14]. The bottom-up model focuses on the words, phrases, sentences, and other details in the text. In comparison, the top-down model focus on the predictions before reading and summarizations after reading, which always aims to understand the gist of the article rather than the meaning of each word [14]. Grabe investigated that reading needs both top-down and bottom-up, which makes it more effective [15]. The interactive model produced in that requirement is based on information from various sources, such as orthography, vocabulary, syntax, semantic knowledge, and patterns. When people read, the decoding and summarization processes can support each other through an interactive mode.

Reading is a combination of vocabulary and sentences, which requires the comprehensive ability of participants. Learners can improve their reading ability by combining intensive reading and extensive reading with reading models. More and more researchers have paid attention to the role of morphological awareness in language learning because of its importance. Although there are many studies on decoding and reading modes, researchers rarely focus on the morphological awareness of Chinese EFL adult learners. This article will review related studies and discuss the following aspects: the relationship between morphological awareness and reading comprehension and the effectiveness of morphological awareness training on the improvement of language level of Chinese EFL adult learners.

\section{MORPHOLOGICAL AWARENESS AND READING COMPREHENSION}

Based on the theories of morphological awareness and reading comprehension, firstly, it discussed that the influence of morphological awareness on the reading comprehension of English native adult speakers. Guo and colleagues investigated that question in their study [16]. They recruited undergraduate and graduate students in public college and assigned them to finish two phases test. They adjusted the Wug test according to the characteristics of adults, emphasizing the acquisition of plurals, the understanding of verb conjugations, and comparative and superlative adjectives to test adult morphological awareness [17]. After that, they also used the Nelson-Denny reading test and the Gates-MacGinitie reading test (4th ed.) to assess the participants' reading comprehension ability $[18,19]$. Combining the results of the two phases, the researchers found that for the adults who are native English speakers, the influence of morphological awareness on reading comprehension is direct. What's more, vocabulary knowledge always impacts independently reading comprehension as a mediator. According to this article, it can be summarized that morphological awareness has an irreplaceable status in reading comprehension for English native adult speakers.

However, different mother tongues may lead to a different relationship between adults' morphological awareness and reading comprehension. Native English 
speakers may rely on phonological awareness in their learning, but Chinese people may depend on morphological awareness more due to their native language [4]. As mentioned above, morphological awareness is an essential competency for both Chinese and English learning, so it is critical to determine whether the relationship between morphological awareness ability and English learning is explicit. Dong and colleagues focused on the relationship between morphological awareness and reading comprehension [20]. They involved Chinese primary, secondary, and college students. They investigated that more significantly correlated data between morphological awareness and reading comprehension in Chinese reading texts or English reading texts is significantly higher than that of phonological awareness and orthographical skill through systematic reviews and meta-analyses. This study involved a variety of measurements to evaluate the reading comprehension, including Gates-MacGinitie Reading Test, Lowa Tests of Basic Skills, Group Reading Assessment and Diagnostic Evaluation, Diagnostic Reading Analysis, Gray Oral Reading Test, Woodcock Reading Mastery Test, Woodcock Language Proficiency Battery, Woodcock-Johnson Test of Achievement and other researcher-developed tests. The standardized test of morphological awareness is based on morpheme production and morpheme judgment. Most studies focus on the association and relationship between reading comprehension, and morphological awareness has two phases to combine. In the study by Dong et al., they investigated that morphological awareness had the strongest correlation with reading comprehension than phonological awareness and orthographical skill. Thus, morphological awareness is vital for Chinese EFL adult learners to learn English in reading comprehension.

According to the above study, it can be known that morphological awareness influences reading comprehension in both Chinese and English. What specific impact morphological awareness has on the growth of the development of Chinese EFL adult learners' reading comprehension needs to be discussed. Xue and Jiang did a longitudinal study investigating the relationship between morphological awareness and reading comprehension [21]. They evaluated learners' ability to read compression using the Gates Macginitie reading comprehension (form 4, level F). They were adapted to test the English morphological awareness by including the task of generating English derivative words and compound words. After that, they indicated the relevance between morphological awareness and reading comprehension via the results of pre-tests and post-tests. As one of the cognitive skills related to reading, morphological awareness is actively related to the development of bilingual reading. In the study, researchers demonstrated that English derivative and compound word production tasks predicted reading comprehension levels nine months later. Therefore, this article strongly supports that morphological awareness effectively affects Chinese adult EFL learners' reading comprehension as a predictor.

\section{THE EFFECTIVENESS OF MORPHLOGICAL AWARENESS TRAINING}

The above studies demonstrated morphological awareness is indeed a predictor in reading comprehension. If it is really so important for reading comprehension, it will be possible to intervene in morphological awareness will improve reading comprehension. In the study by Zhang and Zou, they investigated the influence of explicit morphological instruction on reading comprehension [22]. They recruited English major students, which selected intensive reading classes in a Chinese university. They adopted the quasi-experimental control group design and controlled the teaching in communicative activities, reading activities, and extended activities during each unit. During the training process, the researchers gave explicit morphological instruction to participants, which directly instructed them to identify complex new words or teach the segmentation and meaning of different word structures, providing students with additional examples. Although explicit morphological instruction does not obviously positively affect text-based reasoning and comprehension ability, it positively affects word-meaning reasoning ability. They indicated that the intervention directly affects vocabulary acquisition, while there is no significant impact on reading comprehension. This study does not seem to support the direct influence of morphological awareness on reading comprehension of Chinese EFL adult learners, so they support an indirect relationship. At the same time, it seems to imply morphological awareness training can only affect the vocabulary factor and then affect reading comprehension.

The results of this study on morphological awareness above might be contradictory because it does not have direct evidence to connect morphological awareness with reading comprehension. Thus, further examination of the relationship is needed to confirm whether there is a direct impact. Zhang and Koda assessed the base identification and lexical reasoning to justify the direct and indirect influence of morphology on second language vocabulary knowledge and reading comprehension in a group of adult EFL learners [23]. They state that the differences between L2 morphology and reading comprehension can be attributed to their common differences with vocabulary knowledge. At the same time, they have not found a functional relationship between morphological awareness and reading comprehension, probably because the direct influence of morphological awareness on reading comprehension is 
limited. Indeed, morphological awareness has a significant indirect influence on reading comprehension, only through the mediation of vocabulary knowledge and multiple mediations of lexical reasoning and vocabulary knowledge, so the unique contribution of morphological awareness to reading comprehension can be attributed to the mediating effect of lexical reasoning ability. In addition, the morphological task in the previous research only involves the learner's ability to segment unfamiliar English derivative words into morphological components and recognize the basic form of the target word. In contrast, this morphological insight may have a limited direct contribution to reading comprehension. Its influence on reading comprehension may have to be adjusted by words reasoning ability and vocabulary knowledge. That is reflected in the low correlation between the morphological awareness measurement results and the five comprehension subskills. This article seems to support the idea of morphological awareness's indirect influence on reading comprehension.

Different aspects of morphological awareness training are likely to have different effects on reading comprehension. As there are not many systematic researches focus on these questions about Chinese EFL adult learners and Iranian and Chinese have similarities in language acquisition, they also need the supports of morphological awareness [24]. Hence, this part drew on Iranian research to determine whether its aspects of morphological awareness training affected reading comprehension. Ghasemi and Vaez-Dalili evaluated the effect of three methods of morphological awareness, including textual enhancement, metalinguistic explanation, and morpheme recognition task, on reading comprehension [24]. They assigned participants into 3 groups used two tests to examine Iranian EFL adult learners whose language level is in intermediate. Participants were required to learn the same roots, suffixes, and affixes in the study (The metalinguistic explanation group obtained lists and explanations through the book "word formation"; the textual enhancement group learned roots, suffixes, and affixes through underscores and bold; the morpheme recognition task group needed to analyze the components of the target word and analyzes the meaning of the affixes without assistance). They indicated that the progress of EFL learners' reading comprehension was attributed to morphological awareness, and the L2 derived morphological awareness contributed to L2 reading comprehension. In addition, according to the existing research results, regarding the development of EFL learners' reading comprehension through morphological awareness, it was found that metalinguistic explanation has made the biggest contributions to the reading comprehension of EFL learners. Text enhancement is secondly important in this aspect. In addition, another study conducted by
Amirjalili and Jabbari focuses on the role of morphological instruction to Iranian EFL adult learners. They suggested that language learners' acceptance of the explicit instruction of derived morphology positively impacts reading comprehension, and morphological awareness training can help learners understand the meaning of complex words. The studies, which are focused on the Iranian EFL learners, also showed that explicit training is helpful to English learning [25]. Both studies are about morphological awareness training in other native languages. Their findings suggested that morphological awareness training had a direct impact on reading comprehension.

Furthermore, Li studied specific morphological awareness training, which investigates the relationship between derivative morphological awareness training and reading comprehension [26]. Derivation can be classified as a set of operations on morphemes that derive other morphemes. Derived morphology is a structure conducive to changing various words through students' ability, identifying the relationship between various morphological structures, and making new derivations of known words [27]. He measured comprehensive language proficiency in a group of master students using tests, an English level checklist test, a vocabulary test, an appropriate word matching test, a direct test of morphological knowledge, reading comprehension, and a test of current problems participants have. After that, the researcher found that derivational morphological awareness instruction and reading comprehension ability were closely related to each other. Derivative morphological awareness plays an important role in expanding the extra vocabulary (lexical comprehension) and reading comprehension of adult language learners. Besides, The research results show that morphological awareness training has two effects on reading comprehension. One is that derivative morphological awareness training plays an important role in expanding the extra vocabulary and reading comprehension of Chinese EFL adult learners. Other factors such as reading skills and vocabulary still affect the relationship between English foreign language students' derivative awareness and reading comprehension. Based on this article, it can be found that derivative morphological awareness training can also directly affect the reading comprehension of Chinese EFL adult learners.

\section{LIMITATION AND FUTURE DIRECTION}

Obviously, the existing theoretical research only pays attention to the direct relationship of morphological awareness to English reading comprehension. They ignored the different mediators of Chinese EFL adult learners that affect reading comprehension. At the same time, morphological 
awareness and its training are vital for Chinese EFL adult learners to improve their English reading ability. In addition, systematic researches on Chinese EFL adult learners' morphological awareness training still lack. Indeed, existing studies are limited to a developmental stage, and there are few longitudinal studies. Currently, only one of the researches reviewed is a longitude survey, and the rest are cross-sectional studies. From cross-sectional research, it is difficult for people to track their development and dynamic changes.

Based on the existing researches, future studies can focus on the ways and mediators through which morphological awareness affects the English reading comprehension of Chinese EFL adult learners. Due to the lack of systematic research on morphological awareness training, researchers can design different morphological awareness training for Chinese adult learners to acquire English knowledge in the future, allowing further investigations about how morphological awareness runs impact English reading comprehension. According to the limitation mentioned, longitudinal studies can be more applied in the process of studying the relevance of morphological consciousness and reading comprehension, which allows further understanding of morphological awareness and the dynamic relationship between reading comprehension and morphological awareness. Therefore, more efficient trainings can be improved.

\section{CONCLUSION}

This article mainly reviewed the relationship between morphological awareness and reading comprehension of Chinese EFL adult learners and the impact on morphological awareness training. According to the above analysis, it is undeniable that morphological awareness has an important position that cannot be ignored in the reading comprehension of both native English speakers and Chinese English learners. It was also found that morphological awareness could effectively affect reading comprehension, including direct and indirect effects, which have a direct association. The morphological awareness influenced reading indirectly through vocabulary comprehension and spelling on reading. Moreover, morphological awareness can predict the reading comprehension of Chinese EFL adult learners. Due to the important role of morphological awareness, how to effectively intervene in morphological awareness for English reading comprehension needs to be paid attention to.

Although some research does not seem to support the direct influence of morphological awareness on Chinese EFL adult learners' reading comprehension, morphological awareness training can only affect vocabulary factors. It in turn affects reading comprehension, but other studies have found the direct and indirect effects of morphological awareness training in reading comprehension of Chinese EFL adult learners. At the same time, regardless of the influence of different aspects of morphological awareness training, morphological awareness training is directly related to the development of reading. What's more, research results of derivational morphological awareness training show that morphological awareness training directly impacts reading comprehension, and derivative morphological awareness can also directly affect reading comprehension. Indeed, existing research on Chinese EFL adult learners is still insufficient, requiring more researchers to perfect it.

\section{REFERENCES}

[1] Carlisle, J. F. (1995). Morphological awareness and early reading achievement. In L. B. Feldman (Ed.), Morphological aspects of language processing (pp. 189-209). Hillsdale, NJ: Erlbaum.

[2] Tyler, A., \& Nagy, W. (1989). The acquisition of English derivational morphology. Journal of Memory and Language, 28, 649-667.

[3] Cunningham, A., \& Stanovich, K. E. (1997). Early reading acquisition and its relation to reading experience and ability 10 years later. Developmental Psychology, 33, 934-945.

[4] McBride Chang, C., Shu, H., Zhou, A., Wat, C. P., \& Wagner, R. K. (2003). Morphological Awareness Uniquely Predicts Young Children's Chinese Character Recognition. Journal of Educational Psychology, 95(4), 743-751.

[5] Carlisle, J. F. (2000). Awareness of the structure and meaning of morphologically complex words: Impact on reading. Reading and Writing: An Interdisciplinary Journal, 12, 169-190.

[6] Nagy, W. E., Berninger, V. W., \& Abbott, R. D. (2006). Contributions of morphology beyond phonology to literacy outcomes of upper elementary and middle-school students. Journal of Educational Psychology, 98, 134-147.

[7] Li, W., Anderson, R. C., Nagy, W., \& Zhang, H. (2002). Facets of metalinguistic awareness that contribute to Chinese literacy. In W. Li, J. S. Gaffney, \& J. L. Packard (Eds.), Chinese children's reading acquisition: Theoretical and pedagogical issues (pp. 87-106). Boston: Kluwer Academic.

[8] Chao, Y. R. (1976). Aspects of Chinese sociolinguistics: Essays. Stanford, CA: Stanford University Press.

[9] Snow, C. (2002). Reading for Understanding: Toward an RandD Program in Reading Comprehension. Arlington, VA: Rand Corporation 
[10] Song, M. J. (1998). Teaching reading strategies in an ongoing EFL university reading classroom. Asian Journal of English Language Teaching, 8(1), 41-54.

[11] Hedge, T. (2003). Teaching and learning in the language classroom. UK: OUP.

[12] Pollard-Durodola, S. D., Gonzalez, J. E., Simmons, D. C., Kwok, O., Taylor, A. B., Davis, M. J., \& Simmons, L. (2011). The effects of an intensive shared book-reading intervention for preschool children at risk for vocabulary delay. Exceptional Children, 77(2), 161-183.

[13] Yang, W., Dai, W.,\&Gao, L. (2012). Intensive Reading and Necessity to Integrate Learning Strategies. English Language and Literature. 2(1), 55-63.

[14] Saito, D., \& Yamaura, T. (2013). A New Approach to Programming Language Education for Beginners with Top-Down Learning. International Journal of Engineering Pedagogy, 3(S4), 16-21.

[15] Alyousef, H. S. (2005). Teaching Reading Comprehension to ESL/EFL Learners. The Reading Matrix, 5(2), 143-154.

[16] Guo, Y., Roehrig, A. D., \& Williams, R. S. (2011). The Relation of Morphological Awareness and Syntactic Awareness to Adults' Reading Comprehension: Is Vocabulary Knowledge a Mediating Variable? Journal of Literacy Research, 43(2), 159-183.

[17] Berko, J, (1958). The child's learning of English morphology. Word, 14, 150-177.

[18] Brown, J. I., Fishco, V. V., \& Hanna, G. (1993). Nelson-Denny Reading Test. Chicago, IL: Riverside.

[19] Gates, A. I., \& MacGinitie, W. H. (2000). GatesMacGinitie Reading Tests (4th ed.). Boston, MA: Riverside.

[20] Dong, Y., Peng, S.-N., Sun, Y.-K., Wu, S. X.-Y., \& Wang, W.-S. (2019). Reading Comprehension and Metalinguistic Knowledge in Chinese Readers: A Meta-Analysis. Frontiers in Psychology, 10, 30373037.

[21] Xue, J., \& Jiang, X. (2017). The developmental relationship between bilingual morphological awareness and reading for Chinese EFL adult learners: a longitudinal study. Reading \& Writing, 30(2), 417-438.

[22] Zhang, H., \& Zou, W. (2020). Morphological Intervention in Promoting Higher-Order Reading Abilities among College-Level Second Language
Learners. Sustainability (Basel, Switzerland), 12(4), $1465-$.

[23] Zhang, D., \& Koda, K. (2012). Contribution of morphological awareness and lexical inferencing ability to L2 vocabulary knowledge and reading comprehension among advanced EFL learners: testing direct and indirect effects. Reading \& Writing, 25(5), 1195-1216.

[24] Ghasemi, B., \& Vaez-Dalili, M. (2019). Effect of Three Methods of Morphological Awareness on Iranian Intermediate EFL Learners' Reading Comprehension. International Journal of Instruction, 12(2), 623-638.

[25] Amirjalili, F., \& Jabbari, A. A. (2018). The impact of morphological instruction on morphological awareness and reading comprehension of EFL learners. Cogent Education, 5(1), 1523975-.

[26] Li H.. (2018). The significance and implication of teaching derivational morphology for Chinese 12 learners. US-China Foreign Language, July 2018, Vol. 16, No. 7, 351-369.

[27] Zhang, H. (2014). Morphological awareness in vocabulary acquisition among Chinese-speaking children: Testing partial mediation via lexical inference ability. Reading Research Quarterly, 50(1), 129-142. 